\title{
Thermodynamic Simulation of Essentuki Type Mineral Water Formation
}

\author{
Oxana A. Limantseva ${ }^{1, *}$, and E.G. Potapov ${ }^{2}$ \\ ${ }^{1}$ Vernadsky Institute of Geochemistry and Analytical Chemistry Russian Academy of Sciences, \\ Moscow \\ ${ }^{2}$ Pyatigorsk State Research Institute Balneology Federal Medical-Biological Agency, Pyatigorsk, \\ Russia
}

\begin{abstract}
Thermodynamic models of Essentuki and Nagutsky fields of Caucasian Mineral Waters deposits (KMW) are developed. The models are based on laboratory studies of core samples of aptian-albian lower Cretaceous rock dissolution. The rock samples were disintegrated up to $0.25 \mathrm{~mm}$ grains. The rock grains were mixed with distilled or mineral waters and the mixtures were kept at $20-25^{\circ} \mathrm{C}$ and $65-70^{\circ} \mathrm{C}$, carbon dioxide pressure of $4.04 \mathrm{MPa}$. The results of experimental and thermodynamic modeling are showed that aqueous solution composition formed, in particular, microcomponent concentrations, depends on the rock cement composition (clayey, calcic, siliceous, ferriferous, chloritic, zeolitic phosfatic, sulfatic or mixed) and on the percentage of the microelement mineral-bearing in the water-bearing rock. Also the aqueous solution composition depends on temperature and $\mathrm{CO}_{2}$ partial pressure in the silt rain water $-\mathrm{CO}_{2}$ system. Thermodynamic modeling of the system confirmed gypsum dominant role in sulfate type water formation against pyrite role.
\end{abstract}

\section{Introduction}

Thermodynamic modeling was done using HCh Code designed by Yu.V.SHVAROV $[1,2]$. The thermodynamic models of carbon dioxide mineral water of Essentuki and Nagutsky fields of Caucasian mineral water (KMW) region were formed for the studies of microelements accumulation in mineral water. Verification of the models were done by comparison of simulation and experimental studies results.

\section{Statement of the problem}

Two water-bearing horizons (Paleocene and Upper Cretaceous) are studied. Paleocene one consists of mergels and sandstones of Essentuki suite. Carbon dioxide cold and chloridehydrocarbonate sodium waters of medium and high salinity (Essentuki-4 and Essentuki-17) are there. Four types of mineral waters (medical cure mineral water Essentuki-17, table water Essentuki-4, Borjomi type Nagutsky-26 and Nagutsky-56 waters) are in Nagutsky field. Chemical composition of the waters is the same as widely known Borjomi mineral water. Chemical composition of "sodic" waters of production wells of the Essentuki and Nagutsky fields of mineral waters is given in Table below. The composition simulation is provided for the waters studied.

\footnotetext{
*Corresponding author: 1liimaa@yahoo.com
} 
Table. The water chemical composition taken from production wells.

\begin{tabular}{|c|c|}
\hline $\begin{array}{l}\text { Number } \\
\text { well }\end{array}$ & Formula of the chemical composition \\
\hline 9 bis & $\mathrm{CO}_{2} 0.58 \mathrm{M} 12.2 \frac{\mathrm{HCO}_{3} 69\left(\mathrm{Cl} 30 \mathrm{SO}_{4} 1\right)}{(\mathrm{Na}+\mathrm{K}) 93(\mathrm{Ca} 4 \mathrm{Mg} 3)} \mathrm{HBO}_{2} 0.051 \mathrm{pH} 7.1 \mathrm{~T} 42^{\circ} \mathrm{C}$ \\
\hline $26-\mathrm{H}$ & $\mathrm{CO}_{2} 0.7 \mathrm{M} 5.2 \frac{\mathrm{HCO}_{3} 81\left(\mathrm{Cl} 18 \mathrm{SO}_{4} 1\right)}{(\mathrm{Na}+\mathrm{K}) 96(\mathrm{Ca} 4 \mathrm{Mg} 3)} \mathrm{H}_{2} \mathrm{SiO}_{3} 0.054 \mathrm{pH} 6.9 \mathrm{~T} 56^{\circ} \mathrm{C}$ \\
\hline 43 & $\mathrm{M} 5.8 \frac{\mathrm{HCO}_{3} 74-77(\mathrm{Cl} 19-20)\left(\mathrm{SO}_{4} 3\right)}{(\mathrm{Na}+\mathrm{K}) 98(\mathrm{Ca} 1 \mathrm{Mg} 1)} \mathrm{H}_{2} \mathrm{SiO}_{3} 0.034-0.046 \mathrm{pH} 7.4-7.6 \mathrm{~T} 58^{\circ} \mathrm{C}$ \\
\hline $17 \mathrm{bis}$ & $\mathrm{CO}_{2} 1.9 \mathrm{M} 8.9 \frac{\mathrm{HCO}_{3} 62 \mathrm{Cl} 38}{(\mathrm{Na}+\mathrm{K}) 91} \mathrm{pH} 6.6 \mathrm{~T} 11.9^{\circ} \mathrm{C}$ \\
\hline
\end{tabular}

The static and dynamic models of the rock leaching have been developed. The models describe geological structures of Nagutsky and Essentuki mineral water fields (fig. 1). In general the scheme of modeling is the following (fig. 2): horizontal axis is $\mathrm{P} \mathrm{CO}_{2}$, vertical axis is temperature. Its dependence is the change of properties with deep.

The water motion is described by transfer of water portion from previous block-reactor into subsequent one. So diagonal is the water motion from reservoir with temperature of $10^{\circ} \mathrm{C}$ and $\mathrm{PCO}_{2} 0.6$ bar in direction of sinking of water-bearing rocks with temperature $110^{\circ} \mathrm{C}$ and $\mathrm{PCO}_{2}$ equal to 63 bar as it has been done in laboratory studies [3]. Chemical and mineralogical compositions of water-bearing rocks are taken from [4]. Modeling parameter $\mathrm{R} / \mathrm{W}$ ration increases from 0.2 to 2 . The model used is based on all chemical interactions in the water-rock-gas systems: dissolution of solids and gases, redoxy reactions and complexing into aqueous solution, sorption aqueous species on solids are taken into account also [4]. Thermodynamic openness-closeness in respect to gases is the most important factor for mineral water chemical composition formation. The mass ratio of rock to water $(\mathrm{R} / \mathrm{W})$ reacting is critical for interpretation field data.

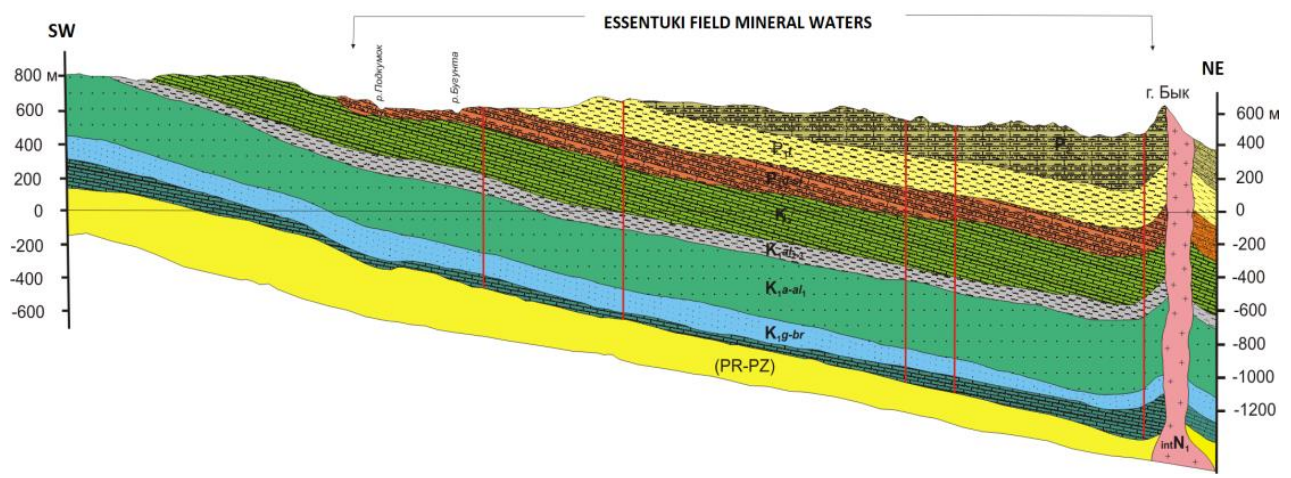

Fig. 1. Schematic litologo-stratigrafic section of the Caucasian Mineral Water artesian basin. 


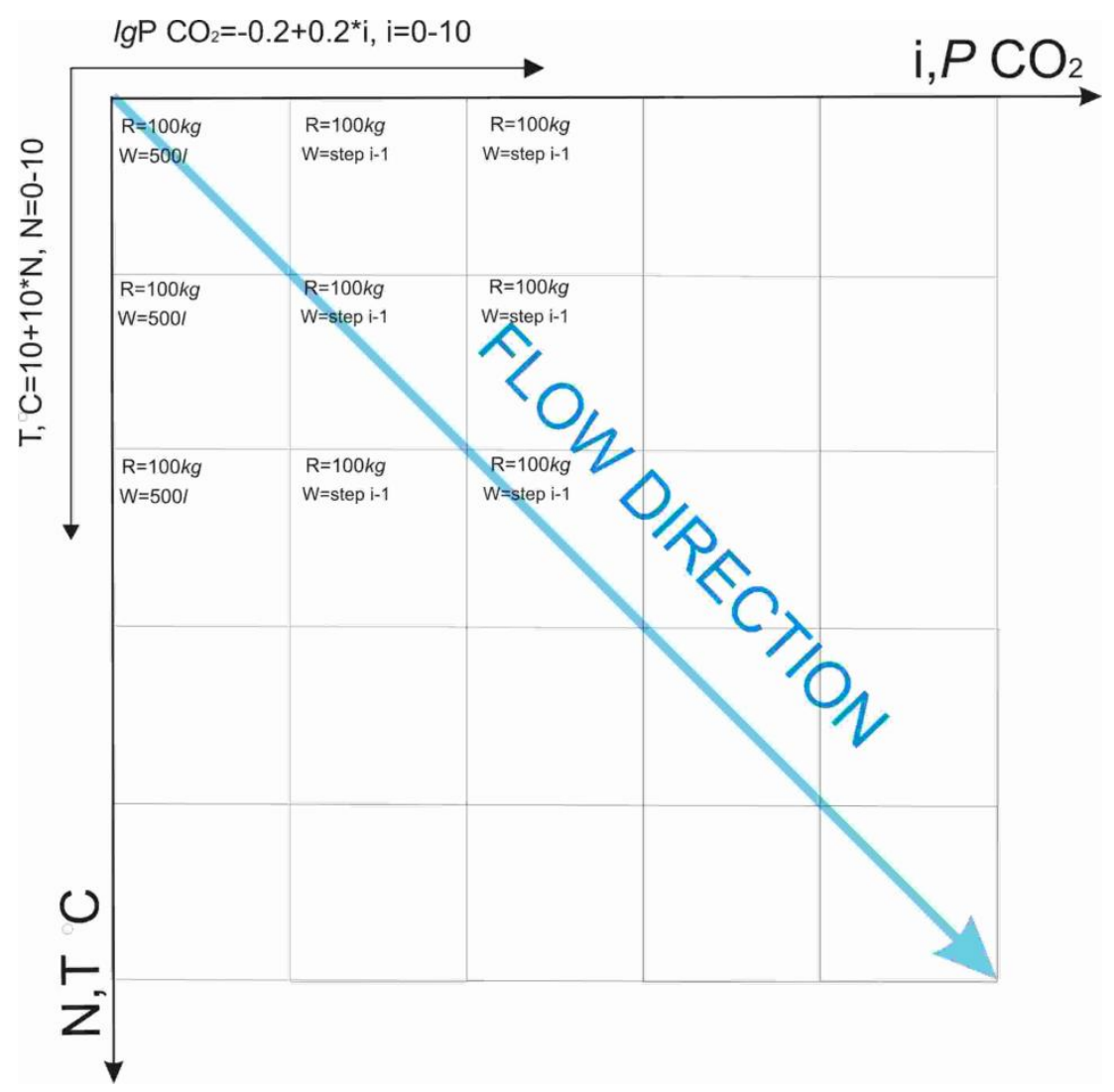

Fig. 2. The scheme of thermodynamic modeling.

\section{The results obtained}

Modeling step is taken for visualization of the forecast of salinity dependence from temperature and $\mathrm{R} / \mathrm{W}$. Using experimental data on chemical elements leaching and thermodynamic simulation results (fig. 2) the polynomial approximation dependence between R/W and experimental salinity is the following: [Salinity, g/ $\left.\mathrm{dm}^{3}\right]=5.7068 \times[\mathrm{R} / \mathrm{W}]^{2}$ $+2.788 \times[\mathrm{R} / \mathrm{W}]+0.1361$. The equation is basic for salinity prognosis (for no carbon dioxide systems).

If the partial pressure of $\mathrm{CO}_{2}$ (in $\lg \mathrm{P} \mathrm{CO}_{2}$ ) equal to 1.3 , in bar, the equation of dependence between salinity and temperature is the following: [Salinity, $\left.\mathrm{g} / \mathrm{dm}^{3}\right]=48.603 \times\left[\right.$ Temperature $\left.^{\circ} \mathrm{C}\right]-0.27$ (with $\mathrm{R}^{2}=0.9877$ ). For certain point the dependence between salinity and partial pressure of carbon dioxide at $10^{\circ} \mathrm{C}$ : [Salinity, $\mathrm{mg} / \mathrm{dm}^{3}=2628.8 \times \ln \left[\mathrm{PCO}_{2}\right.$, bar $]+9923.5\left(\mathrm{R}^{2}=0.9575\right)$.

Using the step flow reactor for simulation of water filtration through rock under certain carbon dioxide pressure (it corresponds results of experimental studies on leaching), the dependence between boron and silica concentrations and temperature is obtained. The boron concentration riches up to $35 \mathrm{mg} / \mathrm{dm}^{3}$ at $95^{\circ} \mathrm{C}$, i.e. mineral water becomes suitable for medical cure and corresponds to table cure ones. In general temperature is favorable to $\mathrm{B}$ and $\mathrm{Si}$ income. But salinity increase correlates with the silica content decrease growth and it helps B enrichment up to boron type water formation. The following minerals are limited 
aqueous solution chemical composition enrichment: graphite, ankerite, apatite, chlorite, dolomite, fluorite, kaolinite, muscovite, microcline, stilbite, pyrite, quartz, rutile.

The dependence obtained between macro and micro component concentrations of mineral waters and parameters of environment of the mineral waters formation (partial pressure of $\mathrm{CO}_{2}$, temperature, and $\mathrm{R} / \mathrm{W}$ (porosity) [5]) may be used for prognosis of cure quality of the KMW waters. The models obtained are in a good agreement with natural objects. It explains high probability of prognosis.

\section{Summary}

1. The dependence of composition of both main chemical elements and medical cure chemical elements on the environment parameters $\left(\mathrm{CO}_{2}\right.$ partial pressure, temperature, porosity) is the basis for analysis of mineral water change in water-bearing horizon so particular as it is necessary.

2. It is possible to use the dependences obtained for quality prognosis of medical cure properties of particular types of mineral water in KMW. It results in high degree prognosis of the models of Essentuki and Nagutsky deposit types.

\section{References}

1. Yu.V. Shvarov. Geochem. Intern. 37. 6, 646-652 (1999)

2. Yu.V. Shvarov. Geochem. Intern. 46. 8, 834-839 (2008)

3. E.G. Potapov, S.R. Danilov, S.U. Gadzhihanova. Razvedka Ohrana Nedr. 2, 41-45 (in Russian) (2013)

4. S.R. Kraynov, B.N. Ryzhenko, V.M. Shvets, Geochemistry of ground waters (CentrLitNefteGas, 2012)

5. O.A. Limantseva. Geochem. Intern. 52. 11, 979-991 (2014) 